\title{
IMPLEMENTASI WEBSITE PENCARIAN KOS DENGAN NOSQL
}

\author{
Danny Kriestanto', Alif Benden Arnado² \\ 1,2,) Jurusan Teknik Informatika, STMIK AKAKOM Yogyakarta \\ Jl. Raya Janti 143, Karangjambe Yogyakarta \\ e-mail : danny@akakom.ac.id, benden.alif@gmail.com
}

\begin{abstract}
ABSTRAK
Perkembangan teknologi basis data baru tidak seperti basis data relasional pada umumnya. Kini, jumlah data yang sangat besar dan tidak terstruktur mendorong terciptanya basis data jenis baru yang mengarah pada pemanggilan data tanpa menggunakan query. Salah satu penerapannya adalah yang dikenal dengan basis data dengan NoSQL (Not Only SQL). Salah satu contoh RDBMS yang menerapkan ini adalah MongoDB yang menyediakan pendukung teknologi penyimpanan data yang tidak lagi terdapat hubungan antar tabel dan tidak menyimpan data dalam format tabel kaku. Selain itu, skema tabel dibuat fleksibel mungkin untuk menangani perubahan pada isi data.

Karakteristik MongoDB yang mampu menyimpan data dalam model array dianggap cocok apabila diimplementasikan pada aplikasi pencarian kos yang setiap dari datanya memiliki struktur skenario yang berbeda. Basis data MongoDB juga mendukung beberapa bahasa pemrograman untuk dapat melakukan manipulasi data antara lain bahasa pemrograman PHP sedangkan Bootstrap material sebagai bentuk interface dari tampilan aplikasi tersebut.

Hasil penelitian menunjukkan bahwa terdapat banyak perbedaan implementasi basis data dengan NoSQL cenderung lebih rumit jika dibandingkan dengan basis data relasional dalam hal struktur, tipe data, maupun CRUD. Hasil penelitian juga menunjukkan bahwa dibutuhkan dua kali proses untuk menampilkan array di dalam array.
\end{abstract}

Kata Kunci: Basis Data, Bootstrap, Google Maps, Google Street View, MongoDB, Material Design, NoSQL

\begin{abstract}
The new technology of database has moved forward the relational databases. Now, the massive and unstructured data encourage experts to create a new type of database without using query. One of this technology is called NoSQL (Not Only $S Q L)$. One of the developing RDBMS that using this technique is MongoDB, which already supporting data storage technology that is no longer need for structured tables and rigid-typed of data. The schema was made flexible to handle the changes of data. The MongoDB data collecting characteristics in the form of arrays is considered suitable for the implementation of boarding house searching where each of the boarding houses have their own scenario structures. MongoDB also supports several programming language, including PHP with Bootstrap material as interface. The results of the research showed that there are alot of difference in implementing a NoSQL database with the regular relational one. NoSQL databases considered alot more complicated in structure, data type, even the CRUD system. The results also showed that in order to view an array inside another array will need two processes.
\end{abstract}

Keywords: Bootstrap, Database, Google Maps, Google Street View, MongoDB, Material Design, NoSQL

\section{Pendahuluan}

$\mathrm{M}$ eningkatnya perkembangan teknologi aplikasi berbasis web tiap waktu meningkat dengan cepat, begitu pula dengan kebutuhan sistem database untuk menyimpan data yang semakin meningkat menjadikan suatu data menjadi aset yang bernilai tinggi, sehingga menyimpan dan mengelola data dengan ukuran data yang berskala besar kini menimbulkan permasalahan dari skalabilitas, karena pertambahan data yang terjadi setiap saat, sehingga memiliki struktur hubungan relasi yang sangat rumit.

Mengambil contoh pencarian tempat hunian sementara atau dapat disebut kos, pada musim masuk kuliah yang mengambil kuliah tempat jauh dari rumah tinggal sehingga mengharuskan menjadi calon mahasiswa perantauan, sebagai pendatang yang masih belum mengerti tentang suasana baru atau kota yang menjadi tempat tinggal baru sehingga masih kesulitan untuk mencari tempat hunian sementara [1].

Dengan adanya perkembangan teknologi yang berbasis web, maka untuk mencari dan memilih tempat tinggal sementara menjadi merasa mudah dan dapat memilih fasilitas yang dapat diukur sesuai modal untuk sewa tempat tersebut. Munculnya teknologi basis data baru yang tidak seperti database lainnya, database yang menggunakan model basis data NoSQL (Not Only SQL) khususnya MongoDB yang menyediakan pendukung kecepatan database agar tetap optimal, dengan memanfaatkan teknologi penyimpanan data yang berbeda dari Database Relasional, di dalam teknologi basis data ini tidak lagi terdapat relasi antar tabel dan tidak menyimpan data dalam format tabel kaku, skema tabel dibuat fleksibel mungkin yang menangani perubahan pada isi data 
tersebut. Walaupun MongoDB memiliki kecepatan yang lebih dalam proses pengambilan data, namun tetap memiliki kelemahan disisi proses penyimpanan data. Penyimpanan data pada MongoDB yang lebih lambat jika dibandingkan dengan pada basis data relasional [2].

Tujuan utama dalam penelitian ini adalah menghasilkan aplikasi yang menerapkan teknologi informasi dalam hal menyimpan data dengan database NoSQL menggunakan MongoDB dan tujuan berikutnya adalah dapat memberikan info tentang kos yang berada di Yogyakarta berupa sistem berbasis web.

Manfaat utama yang dapat diperoleh adalah untuk meneliti teknologi NoSQL yang tidak memiliki relasi tabel dengan menggunakan basis data MongoDB sebagai tool impementasinya, serta apakah MongoDB ini dapat diimplementasikan dalam aplikasi pencarian kos yang berada di Yogyakarta berupa sebuah sistem berbasis web.

\section{METODE}

Adapun penelitian ini dilakukan dengan tahapan sebagai berikut:

1. Melakukan analisis kebutuhan input (data-data tentang kos, pemilik, harga, dsb)

2. Melakukan pengambilan data pada beberapa lokasi kos langsung dari para pemiliknya.

3. Melakukan analisa data-data yang diperoleh untuk merancang model dari basis data yang akan dibentuk.

4. Membuat diagram alir aplikasi.

5. Mengimplementasikan basis data dengan teknik NoSQL dengan basis data MongoDB

6. Desain aplikasi menggunakan Material Design dengan JSON untuk pertukaran data.

7. Peta yang digunakan adalah peta dari Google Map dan Google Streetmap

8. Menggunakan PaaS (Platform as a Service) millik OpenShift (https://www.openshift.com/) yang harus dikonfigurasi secara manual.

Oleh karena masih adanya ketidaksamaan dalam pendapat mengenai pemodelan yang digunakan untuk basis data berbentuk NoSQL, dalam penelitian ini akan menggunakan DFD sebagai tool untuk membentuk desain perancanannya. Adapun DFD (Data Flow Diagram) level 1 yang digunakan dalam penelitian ini dapat dilihat pada gambar 1.

Perancangan basis data pada NOSQL tidak sama dengan perancangan basis data pada DBMS konvensional. Terdapat perbedaan mendasar pada model, dan juga tipe data-nya. Adapun tabel berubah namanya menjadi Document. Dan semua dokumen yang dibentuk dapat dilihat pada tabel I, tabel II, dan juga pada tabel III.

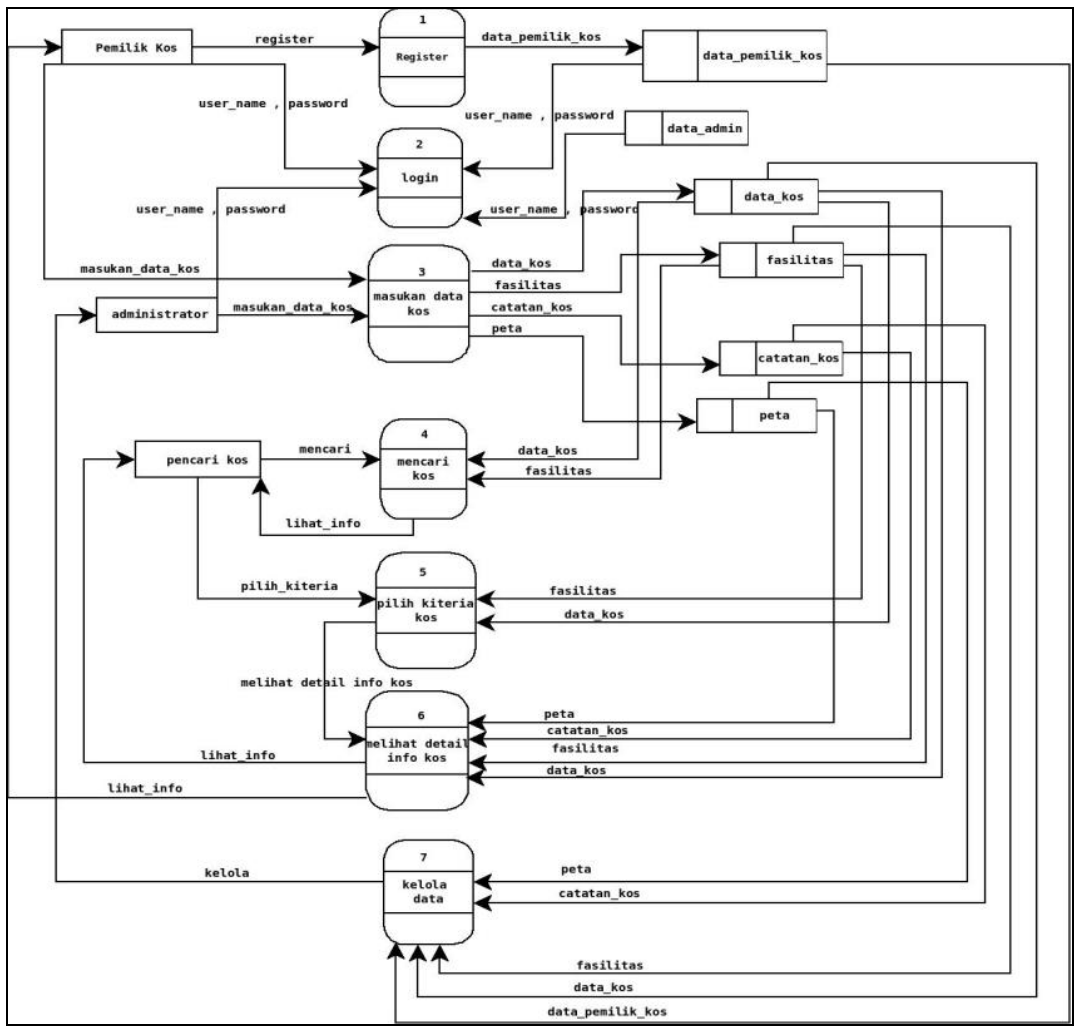

Gambar 1. DFD Aplikasi Pencarian Kos Berbasis Web dan MongoDB 
Tabel I

Document Admin

\begin{tabular}{|c|c|c|}
\hline Key & Type & Deskripsi \\
\hline _id & Objectid & Collection Primary key \\
\hline Nama & String & Nama Administrator \\
\hline User_name & String & User_name \\
\hline Password & String & Password admin \\
\hline Icon_profil & String & Icon profil dashboard administrator \\
\hline
\end{tabular}

Tabel I menunjukkan dokumen admin yang menjelaskan deskripsi, tipe serta kunci tiap atribut yang ada pada dokumen admin. Sedangkan pada tabel II menunjukkan dokumen data pemilik kos yang berisi deskripsi atribut pemilik kos beserta tipe dan key-nya.

Tabel II

Document Data Pemilik

\begin{tabular}{lll}
\hline \hline \multicolumn{1}{c}{ Key } & \multicolumn{1}{c}{ Type } & \multicolumn{1}{c}{ Deskripsi } \\
\hline _id & Objectid & Collection Primary key \\
Nama_pemilik & String & Nama_pemilik \\
User_name & String & User_name \\
Password & String & Password pemilk kos \\
Confirm_password & String & Confirm Password pemilik \\
& & kos \\
Nomor_handphone & String & Nomor Handphone \\
Tgl_daftar & String & Tanggal daftar pemilik kos \\
Icon_profil & String & Icon profil dasboard pemilik \\
& & kos \\
\hline \hline
\end{tabular}

Tabel III

Document data kos

\begin{tabular}{lll}
\hline \hline \multicolumn{1}{c}{ Key } & \multicolumn{1}{c}{ Type } & \multicolumn{1}{c}{ Deskripsi } \\
\hline _id & Objectid & Collection Primary key \\
Tgl_daftar & String & Tanggal daftar kos \\
Nama_pemilik & String & Nama pemilik yang kos \\
Nomor_handphone & String & Nomor handphone pemilik kos \\
Nama_kos & String & Nama kos \\
Jenis_kos & String & Jenis kos baik putra atau putri \\
Ukuran_kos & Object & Ukuran ruangan kos \\
Panjang_kamar & String & Panjang kamar kos \\
Lebar_kamar & String & Lebar kamar kos \\
Status_kos & String & Status_kos ( Tersedia, Full, Sisa ) \\
Alamat_kos & String & Letak alamat kos \\
Alamat_jalan_kos & String & Letak alamat kos berdasarkan maps \\
Map & Object & Map posisi koordinat kos \\
Latitude & String & Garis lintang koordinat kos \\
Longitude & String & Garis bujur koordinat kos \\
Harga_sewa & Object & Biaya sewa kos \\
Harga_sewa & Int & Harga sewa kos \\
Hitungan_sewa & String & Hitungan sewa kos \\
Lama_sewa & String & Lama sewa (1 bln s/d 3 bln, 1 Thn) \\
Fasilitas_kos & Array & Fasilitas yang dimiliki kos \\
Catatan_pemilik & String & Catatan pemilik \\
Foto & Array & Foto sekitar lingkungan kos \\
\hline \hline
\end{tabular}

Untuk tabel III menunjukkan rincian dari dokumen data kos yang memuat data-data mengenai data pemilik kos, letak kos beserta koordinat latutide dan longitudenya, harga sewa kamar kos, fasilitas dan lainnya.

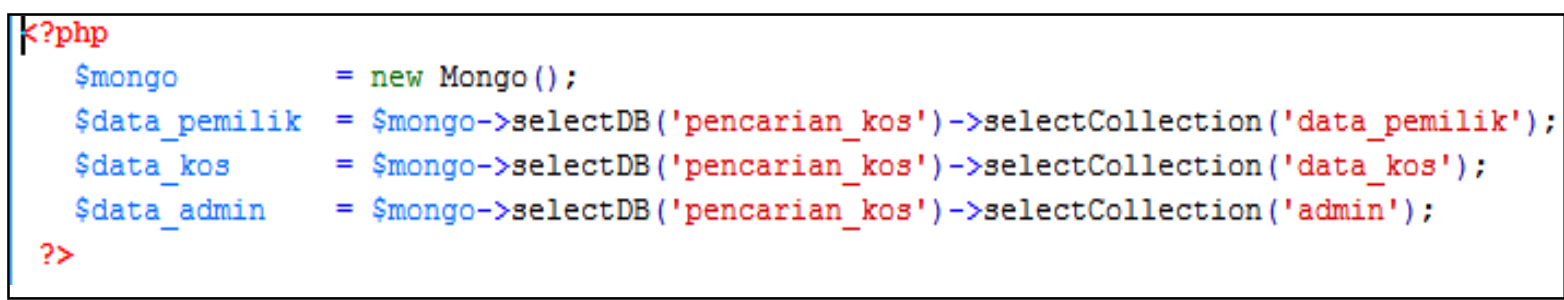

Gambar 2 Pemanggilan Basis Data MongoDB di PHP 


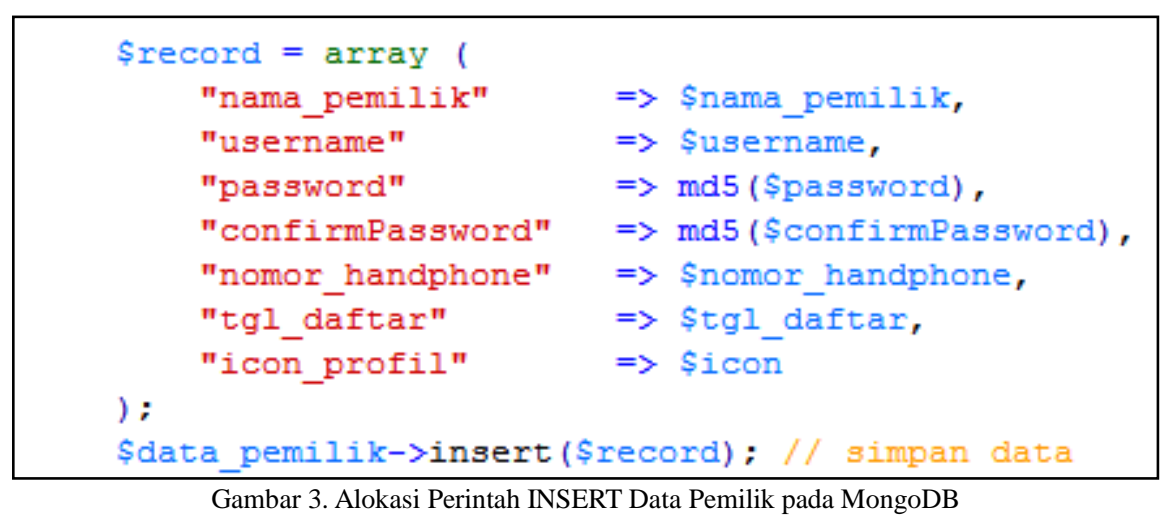

\section{HASIL}

Setiap halaman yang akan dibuat wajib memanggil basis data MongoDB dibuat dengan skrip pembuatan objek variabel \$mongo dengan metode class library Mongo(), seperti yang tampak pada gambar 2. Gambar 3 menunjukkan potongan perintah untuk memasukkan data ke dalam basis data dari sisi PHP. Dari gambar tersebut terlihat bahwa proses pengisian data tidak menggunakan perintah DML seperti biasanya digunakan, namun dengan menggunakan array.

Jika dilihat dari strukturnya, basis data yang dibuat dengan menggunakan MongoDB sekilas tidak banyak perbedaannya dengan basis data relasional. Akan tetapi, sesungguhnya ada beberapa perbedaan yang sangat mendasar. Misalkan pada tabel II, terdapat sebuah tipe data array. Array tidak terdapat pada basis data relasional karena dalam 1 record tidak diijinkan menyimpan data yang non-atomik. Akan tetapi, pada MongoDB hal ini sangat dimungkinkan. Salah satu penggunaan array dalam penelitian ini adalah untuk menunjukkan fasilitas kos.

Pada [3], jika menggunakan basis data relasional biasa, kolom tersebut dapat dipecah menjadi tabel terpisah untuk memudahkan pencarian dengan query. Namun, pada MongoDB hal itu tidak diperlukan, sehingga fasilitasfasilitas kos dapat dicari per item-nya walaupun tidak berada pada field yang berbeda layaknya basis data relasional. Walaupun demikian, setiap fasilitas tersebut harus dimasukkan ke dalam array (Array di dalam sel sebuah record) [4]. Di dalam MongoDB, sebuah record merupakan sebuah array. Jadi, dalam implementasinya, tipe data array merupakan sebuah array di dalam array. Untuk menampilkan data tersebut diperlukan dua kali proses. Hal ini disebabkan oleh karena struktur dari array itu sendiri. Adapun contoh implementasi ini dapat dilihat pada gambar 2.

Dalam implementasi basis data relasional, latitude dan longitude akan disimpan terpisah pada kolom yang berbeda, namun seperti yang terlihat pada gambar 2, objek "map" menyimpan 2 buah nilai array yakni "latitude" dan "longitude". Penggunaan array juga dilakukan pada "ukuran_kos", "harga_sewa", dan "fasilitas_kos". Adapun obyek "fasilitas_kos" menyimpan array data yang bervariasi oleh karena tidak semua kos memiliki fasilitas yang sama.

\section{PEMBAHASAN}

Implementasi aplikasi berbasis web dengan menggunakan MongoDB memerlukan beberapa pengaturan terlebih dahulu. Tidak seperti MySQL dan basis data relasional lainnya, MongoDB perlu diatur secara manual untuk menghubungkan PHP dengan MongoDB, dengan mengedit file php.ini dan menambahkan "extension=mongo.so". Dalam implementasi, oleh karena aplikasi ini mengunggah lebih dari satu gambar maka diperlukan sebuah skrip agar data tersebut disimpan pada database MongoDB dengan struktur array di dalam array. Pada akhirnya, teknik sederhana yang digunakan adalah dengan memindahkan gambar ke dalam folder yang sebelumnya sudah diciptakan dengan skrip terlebih dahulu. Berikutnya, perlu membuat URL dari gambar tersebut untuk disimpan di dalam database.

Untuk menampilkan data, terutama menampilkan data yang menggunakan array di dalam sebuah array, dibutuhkan setidaknya dua buah proses. Masing-masing untuk memproses satu array, mulai dari array yang berada paling dalam, sebelum array pada bagian luar. Proses ini tampak kemiripannya dengan subquery pada basis data relasional namun lebih rumit karena tidak menggunakan bahasa SQL. Perintah untuk basis data NoSQL untuk menampilkan data semacam ini membutuhkan pengkodean sendiri.

Namun, oleh karena MongoDB merupakan basis data yang tidak terstruktur, apabila terjadi perubahan terhadap struktur collection, maka data-data yang sudah ada sebelumnya tidak perlu disesuaikan kembali. Mongo DB memungkinkan adanya penambahan, penghapusan, dan perubahan struktur data tanpa mengubah data yang sudah 
ada sebelumnya. Dengan kata lain, tiap-tiap record data dapat memiliki struktur yang berbeda pada satu collection (tabel) yang sama.

Konfigurasi yang digunakan dalam proses hosting cukup rumit, dan oleh karena menggunakan PaaS maka konfigurasi tersebut wajib dilakukan secara manual. Hingga saat ini, hosting yang dapat digunakan untuk implementasi MongoDB masih yang berbayar dan jumlahnya masih sedikit.

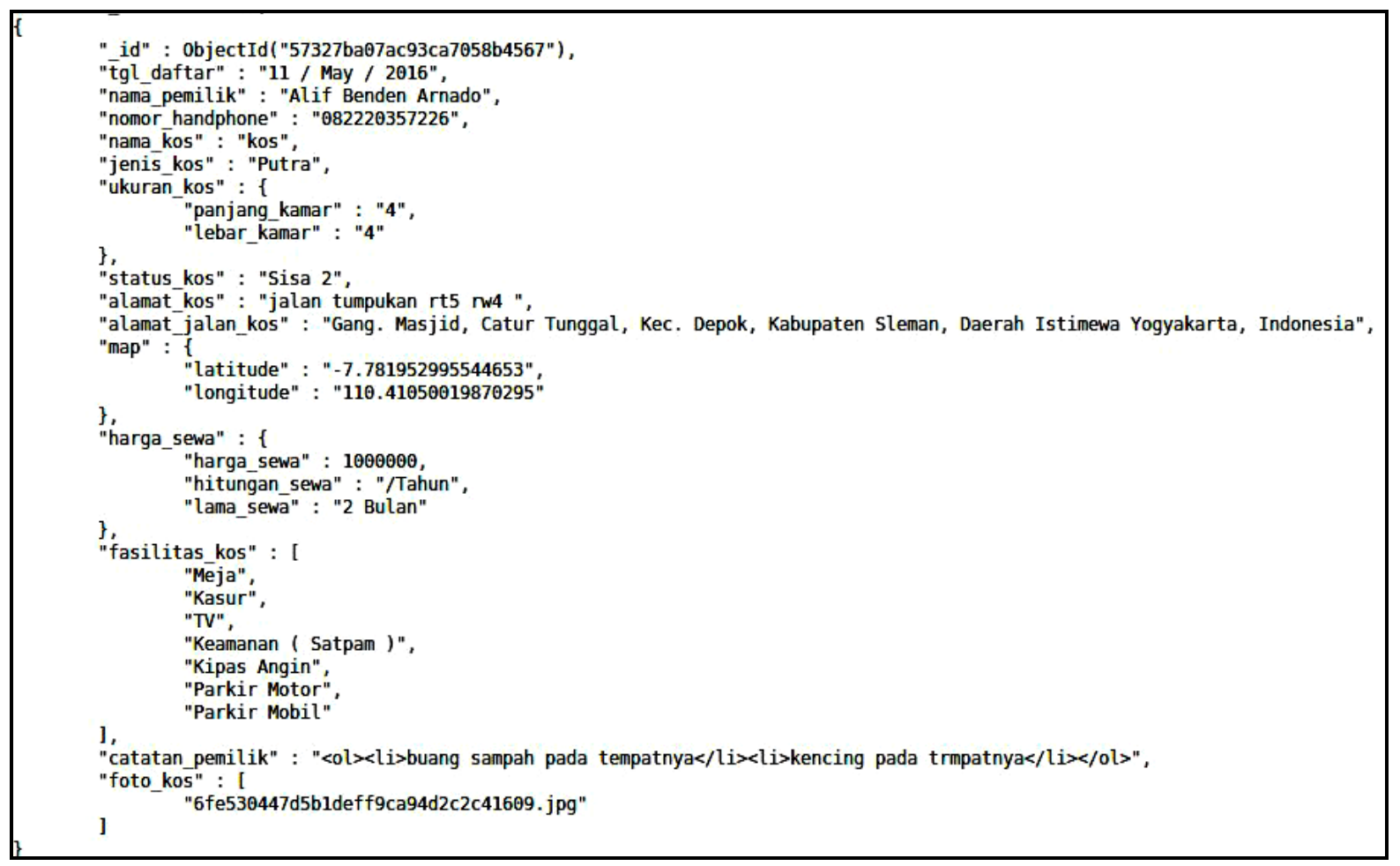

\section{SIMPULAN DAN SARAN}

Berdasarkan penelitian ini, maka dapat ditarik kesimpulan berikut:

1. Implementasi dalam CRUD pada MongoDB dengan PHP dapat dilakukan dengan baik.

2. Pencarian data kos berdasarkan fasilitas dengan menggunakan MongoDB dapat berjalan dengan baik.

3. Adanya waktu untuk inisialisasi struktur collection sehingga dibutuhkan waktu lebih banyak pada saat hendak mengunggah data baru.

4. Penympanan data gambar yang lebih dari satu membutuhkan struktur array di dalam array. Banyaknya array di dalam array tersebut dapat pula menentukan kecepatan unggah data

5. Membutuhkan dua kali proses dalam menampilkan data array dalam array sehingga membuat proses memuat data menjadi lambat.

6. Tidak perlu adanya pembuatan tabel seperti basis data RDBMS. Pada MongoDB dapat dibuat langsung menggunakan array assosiatif agar hasil tersebut berupa JSON.

Berdasarkan hasil evaluasi terhadap aplikasi ini, adapun saran untuk pengembangan selanjutnya adalah:

1. Diperlukan penelitian untuk mencari teknik memuat data dengan lebih cepat.

2. Perlu diteliti lebih jauh seberapa lamakah waktu yang dibutuhkan untuk memuat data apabila aplikasi dengan collection yang lebih banyak dan lebih kompleks. 


\section{REFERENSI}

[1] ___ "Pengertian Kos", http://library.binus.ac.id/eColls/eThesisdoc/Bab2/2009-1-00024-AR\%20Bab\%202.pdf, tanggal akses 31 Januari 2016.

[2] Andi Wahju Raharjo E, Jimmy Sentosa, "Perbandingan Kinerja Data Manipulation Language MongoDB dan SQL Server", http://www.andiwre.itmaranatha.org/jurnal/Paper\%20Andi\%20WRE\%20cs\%20\%20Seminasik\%202013\%20v\%20prosiding.pdf, tanggal akses 26 September 2015, 2013

[3] ___ "PHP MongoDB", http://php.net/manual/en/book.mongo.php, tanggal akses 18 September 2015.

[4] ___ "MongoDB Manual", http://docs.mongodb.org/manual/crud, tanggal akses 18 September 2015. 